2000USD as a instructor for Boehringer -Ingelheim, Novartis and Gebro, Speakers bureau: ND, Ana Milena Millán Arciniegas: None declared, Josep Maria Llobet: None declared, Hector Corominas: None declared DOI: 10.1136/annrheumdis-2019-eular.5637

\section{FRI0677 IMPACT OF COMORBIDITY ON THE USE OF BIOLOGICAL AND TARGETED THERAPY IN RHEUMATIC DISEASES IN THE CLINICAL PRACTICE}

Dmitry Karateev, Hava Hamhoeva, Helen Luchihina, Aminat Tangieva. Moscow Regional Research and Clinical Institute ("MONIKI"), Rheumatology department, Moscow, Russian Federation

Background: Comorbid conditions often accompany rheumatic diseases and can influence the prescription of immunosuppressive therapy. Comorbidity seems to be a factor that is still underestimated in actual practice. Objectives: To study the influence of comorbidity on the prescription of biological and targeted therapies in patients with rheumatic diseases (RD) in clinical practice.

Methods: We perform a retrospective analysis of comorbidity and prescription of biological and targeted immunosuppressors in a group of inpatients with systemic autoimmune RD in rheumatology department. From January 2018 to January 2019, 218 patients with inflammatory RD hospitalized - $146(67,5 \%)$ women, mean age 50.6 $\pm 14,6$ years. Diagnoses: rheumatoid arthritis - 83 patients, spondyloarthritides - 80 , systemic lupus erythematosus - 19, systemic scleroderma - 16, ANCA-associated vasculitides - 10, other conditions - 10 patients. Biologics were used in 117 $(53,7 \%)$ of patients (anti-TNFs - 64 patients, rituximab - 18, tocilizumab - 16, abatacept - 8, secukinumab - 4, ustekinumab - 4, tofacitinib - 3 patients). We examined patients for comorbidities through careful examination of the history, medical records, and general therapeutic laboratory and instrumental screening. The Charlson comorbidity index calculated for every patient.

Results: $174(79.8 \%)$ patients had at least 1 comorbid condition. The most frequent comorbidities were type2 diabetes (19,5\% patients), chronic kidney disease (12,6\%), cerebrovascular accidental (11,5\%), ischemic heart disease and chronic heart failure (11\%), chronic liver disease $(7,5 \%)$. Mean Charlson index was $2,16 \pm 2,05$ in total group; it was significantly lower in patients who were treated with biological and targeted therapy $(1,64 \pm 1,8)$ than in patients who did not received this therapy $(2,76 \pm 2,1), p<0,01$. Biologics were prescribed in $81,8 \%$ of patients without comorbidities, in comparison with $55,3 \%$ of patients with Charlson comorbidity index 1 or 2 , and $36,3 \%$ of patients with Charlson index 3 or more.

Conclusion: Comorbidity has a direct impact on the use of biological and targeted therapy in patients with rheumatic diseases in real clinical practice, limiting the ability to control the activity of the disease. It is necessary to develop a general therapeutic strategy for treating comorbid conditions in patients with rheumatic diseases.

\section{REFERENCES:}

[1] Charlson ME, Pompei P, Ales KL, MacKenzie CR. A new method of classifying prognostic comorbidity in longitudinal studies: Development and validation. Journal of Chronic Diseases. 1987; 40 (5): 373-83

Disclosure of Interests: Dmitry Karateev Speakers bureau: Pfizer, Novartis, Janssen, Abbvie, Biocad, MSD, BMS, Hava Hamhoeva: None declared, Helen Luchihina Speakers bureau: Pfizer, Abbvie, Biocad, Aminat Tangieva: None declared

DOI: 10.1136/annrheumdis-2019-eular.8183

\section{FRI0678 PREVALENCE, PATIENT CHARACTERISTICS, AND TREATMENT OF GOUT AND ASYMPTOMATIC HYPERURICEMIA IN JAPAN: CROSS-SECTIONAL STUDY OF A HEALTH INSURANCE CLAIMS DATABASE}

Ruriko Koto ${ }^{1}$, Akihiro Nakajima ${ }^{2}$, Hideki Horiuchi ${ }^{1}$, Hisashi Yamanaka ${ }^{3} .{ }^{1}$ Teijin Pharma Limited, Medical Science Department, Tokyo, Japan; ${ }^{2}$ Teijin Pharma Limited, Pharmaceutical Development Administration Department, Tokyo, Japan;

${ }^{3}$ Tokyo Women's Medical University, Institute of Rheumatology, Tokyo, Japan

Background: The prevalence of gout is increasing worldwide [1,2], but evidence suggests that current treatment practices do not effectively reduce serum uric acid (sUA) levels in many gout patients [3]. In Japan, urate lowering therapy (ULT) is provided to patients diagnosed with asymptomatic hyperuricemia as well as to those with gout. However, the actual treatment situation for asymptomatic hyperuricemia has not been well-documented

Objectives: To assess the prevalence and characteristics of gout and asymptomatic hyperuricemia and the current treatment practices for these conditions in Japan.

Methods: This retrospective cross-sectional study assessed disease prevalence, patient characteristics, prescriptions, proportion of patients achieving target SUA, and incidence of gouty arthritis among 2,531,383 individuals in a database, using data from Japanese health insurance claims and medical check-ups from April 2016 to March 2017.

Results: Gout was diagnosed in $1.1 \%$ (men $1.9 \%$, women $<0.1 \%$ ) of the study population and asymptomatic hyperuricemia in $2.6 \%$ (men $4.1 \%$ women $0.4 \%$ ). Hyperuricemia ( $\mathrm{SUA}>7.0 \mathrm{mg} / \mathrm{dL}$ ) was identified in $13.4 \%$ (men $19.6 \%$, women $1.0 \%$ ) of cases in which sUA level was measured at check-up. ULT adherence was satisfactory (median medication possession ratio [MPR] of $69.0 \%$ for febuxostat and $78.1 \%$ for allopurinol in gout, and $79.5 \%$ and $88.5 \%$, respectively, in asymptomatic hyperuricemia), but most patients were receiving low-dose ULT. The sUA target $(\leq 6.0$ $\mathrm{mg} / \mathrm{dL}$ ) was achieved by less than half of patients treated with either febuxostat or allopurinol (Table). In gout patients, the incidence proportion of gouty arthritis was $47.8 \%$ and the incidence rate was 0.74 flares/person-year.

Conclusion: The prevalence of gout in our study population was low. Japanese physicians often treat gout and asymptomatic hyperuricemia with low-dose ULT, and many patients fail to reach their target sUA suggesting gout management is suboptimal in Japan.

\section{REFERENCES}

[1] Zhu Y, et al. Prevalence of gout and hyperuricemia in the US general population: the National Health and Nutrition Examination Survey 2007-2008. Arthritis Rheum 2011;63(10):3136-41.

[2] Kuo CF, et al. Global epidemiology of gout: prevalence, incidence and risk factors. Nat Rev Rheumatol 2015;11(11):649-62.

[3] Roddy E, et al. Concordance of the management of chronic gout in a UK primary-care population with the EULAR gout recommendations. Ann Rheum Dis 2007;66(10):1311-5

Table

\begin{tabular}{lcccc}
\hline & \multicolumn{2}{c}{ Gout } & \multicolumn{2}{c}{$\begin{array}{c}\text { Asymptomatic } \\
\text { hyperuricemia }\end{array}$} \\
\cline { 2 - 5 } & Febuxostat & Allopurinol & Febuxostat & Allopurinol \\
\hline $\mathrm{N}$ & 8215 & 6521 & 16312 & 14220 \\
Mean prescribed dose & $18.9 \mathrm{mg}$ & $145.6 \mathrm{mg}$ & $16.5 \mathrm{mg}$ & $131.3 \mathrm{mg}$ \\
Median MPR & $69.0 \%$ & $78.1 \%$ & $79.5 \%$ & $88.5 \%$ \\
Proportion of patients achieving & $44.7 \%$ & $33.8 \%$ & $47.8 \%$ & $35.9 \%$ \\
target sUA ( $\leq 6.0 \mathrm{mg} / \mathrm{dL})$ & $(876 / 1960)$ & $(599 / 1771)$ & $(2032 /$ & $(1691 /$ \\
& & & $4254)$ & $4704)$ \\
\hline
\end{tabular}

Disclosure of Interests: Ruriko Koto Employee of: Teijin Pharma Limited Akihiro Nakajima Employee of: Teijin Pharma Limited, Hideki Horiuch Employee of: Teijin Pharma Limited, Hisashi Yamanaka Grant/research support from: AbbVie, Eisai, Bristol-Meyers, Novartis, Behringer, Astellas, Kaken, Nippon-Shinyaku, Pfizer, UCB, Ayumi, Ono, Daiichi-Sankyo, Taisyo-Toyama, Takeda, Tanabe-Mitsubishi, Chugai, Teijin Pharma, Torii, YLbio, Speakers bureau: Bristol-Meyers, Astellas, Pfizer, Daiichi-Sankyo, Takeda, Tanabe-Mitsubishi, Chugai, Teijin Pharma, YLbio

DOI: 10.1136/annrheumdis-2019-eular.4466

\section{FRI0679 PREDICTORS OF DEATH IN 3693 PATIENTS WITH RHEUMATOID ARTHRITIS FOLLOWED FOR UP TO 12 YEARS IN CLINICAL PRACTICE}

Louise Linde ${ }^{1}$, Merete L. Hetland ${ }^{2} .{ }^{1}$ Rigshospitalet, Center for Rheumatology and Spine diseases, Copenhagen, Denmark; ${ }^{2}$ Copenhagen Center for Arthritis Research (COPECARE), Glostrup, Denmark

Background: Patients with RA have shorter life expectancy than the background population. Severe disease, as reflected in high disease activity, comorbid conditions and functional disability have historically been associated with increased mortality (1-2). Mortality after the introduction of 